\title{
Cuspal movement related to different bonding techniques using etch-and-rinse and self-etch adhesive systems
}

\author{
Edson Alves Campos ${ }^{a}$ \\ Marcelo Ferrarezi Andrade ${ }^{b}$ \\ Sizenando Toledo Porto-Neto ${ }^{b}$ \\ Lucas Arrais Campos ${ }^{b}$ \\ José Roberto Cury Saad ${ }^{\mathrm{b}}$ \\ Tatiana Miranda Deliberador ${ }^{a}$ \\ Osmir Batista Oliveira-Júnior ${ }^{b}$
}

\section{ABSTRACT}

Objectives: To investigate the effects of adhesion technique using different contemporary adhesive systems on the cuspal movement in class II composite restorations in human premolar teeth.

Methods: Human premolar teeth were prepared with class II cavities and then restored with composite and etch-and-rinse (Adper Scotchbond Multi Purpose and Adper Single Bond) or selfetch (Clearfil SE Bond and Clearfil S3 Bond) adhesive systems under different bonding techniques (total bonding and selective bonding). The influence of an intermediate layer of flowable composite was also evaluated. The cuspal distance was measured before and after the restorative procedure, and the difference was recorded as cuspal movement. The data were submitted to ANOVA test and Tukey's post hoc comparison procedure test lalpha=0.05).

Results: For all adhesive systems, the teeth restored with selective bonding technique showed lower values of cuspal movement and the use of an intermediary layer of flowable composite did not show any influence on the cuspal movement.

Conclusions: Both the adhesive techniques tested were not able to prevent the cuspal movement. However, selectively bonded class II composite restorations demonstrated lower values of cuspal movement comparing with total bonding technique, and the use of an intermediate layer of flowable composite did not diminish the values of cuspal movement. (Eur J Dent 2009;3:213-218)

Key words: Etch-and-rinse adhesive; Self-etch adhesive; Bonding technique; Cuspal movement.

- a Positivo University.

b Department of Restorative Dentistry, School of Dentistry of Araraquara, São Paulo State University.

- Corresponding author: Edson Alves Campos Rua Professor Pedro Viriato Parigot de Souza, 5300 81280-330 - Curitiba-PR - Brazil

Phone: +55 (41)3317-3403

Fax: +55 (41)3317-3082

E-mail: edson.campos@up.edu.br

\section{INTRODUCTION}

Due to esthetic reasons, resin composite has become widely used as a restorative material in posterior teeth. However, all resin-based materials undergo contraction inherent to the polymerization reaction. ${ }^{1,2}$ It can be observed two types of problems related to polymerization shrinkage of composites: whether the composite 
is weakly adhered to the dental tissues, gaps can be formed; if the adhesive strength exceeds the contraction stress, the restoration maintains an internal tension that pulls the walls of the tooth, reducing the intercuspal distance. ${ }^{3}$ The cuspal movement may be perceived by the patient as post-operative pain and the interfacial debonding at the tooth-restoration interface may lead to marginal staining, pulpal inflammation and secondary caries. ${ }^{4,5}$

Although adhesion is generally associated with the total bonding technique, adhesive systems can be applied in different manners. Krejci and Stavridakis ${ }^{6}$ have defined the adhesion types as following: total bonding - adhesion is established to the entire surface of the cavity; selective bonding - adhesion is restricted to the margins of the preparation; separate bonding - the cavity is sealed by an adhesive system that does not adhere to or is insulated against the restorative material; and secure bonding - adhesion between the restorative material and the adhesive system is not completely eliminated, but is weaker than the adhesion between the adhesive system and the tooth. The selective-bonding technique reduces the factor- $\mathrm{C}$ and, in case of marginal discontinuity, the adhesive functions as a second barrier against penetration of bacteria in dentin. ${ }^{?}$

The aim of this study was to assess the cuspal deflection related to different adhesive techniques (total bonding and selective bonding) and to the utilization of an intermediary layer of flowable composite.

\section{MATERIALS AND METHODS}

One hundred sixty sound extracted human premolar teeth were used in this study. The teeth were stored in $0.1 \%$ tymol solution at $5^{\circ} \mathrm{C}$. All the restorative procedures were made under simulated dentinal hydrostatic pressure, employing a previously described protocol. ${ }^{8}$

A $1.5 \mathrm{~mm}$ diameter glass ball was fixed to each cusp vertex as reference points for intercuspal distance measurements. ${ }^{3}$ Each tooth was subjected to preparation of a large mesio-occlusaldistal (MOD) cavity, with the bucco-lingual width (BLW) of the approximal boxes of the cavity being prepared to two-thirds of the BLW of the tooth and the occlusal isthmus being prepared to half the BLW. The cavity depth at the occlusal isthmus was standardized $(3.0 \mathrm{~mm})$ and the cervical wall was located $1 \mathrm{~mm}$ above the amelocemental junction (ACJ) at the cervical aspect of the proximal boxes. The teeth showing pulpal exposure after the preparation were discarded. Facial and lingual walls of the cavity were prepared parallel. ${ }^{9}$ The initial distance between reference balls was measured with a digital micrometer (Mitutoyo, 293-561, Kanagawa, Japan) and recorded as 'initial distance'.

For the experiment were used different adhesive systems:

- three-step etch-and-rinse adhesive: Adper Scotchbond Multi Purpose - SMP (3M Espe, St Paul, MN, USA);

- two-step etch-and-rinse adhesive: Adper Single Bond - SB (3M Espe, St Paul, MN, USA);

- two-step self-etch adhesive: Clearfil SE Bond

- CSEB (Kuraray Co., Osaka, Japan);

- all-in-one self-etch adhesive: Clearfil S3 Bond - CS3 (Kuraray Co., Osaka, Japan).

After the cavity preparation, the teeth were randomly distributed in sixteen groups $(n=10)$ according to the adhesive protocol (Table 1).

All the materials were applied in accordance with the manufacturer's guidelines. For SMP adhesive system, the dental surface lenamel and dentin) was acid etched with $37 \%$ phosphoric acid gel for 15 seconds, rinsed for 10 seconds and gently dried with absorbent paper to keep the dentinal surface visibly moist. The primer was applied and dried for 5 seconds prior to the application of the adhesive that was light cured for 10 seconds IOptilux 500, Demetron Research Corp., Danbury, CT, USA). The SB adhesive protocol was performed by applying two consecutive coats of self-priming adhesive resin onto the etched dental surface (37\% phosphoric acid gel for 15 seconds), and drying for 5 seconds to evaporate the solvent. The adhesive layer was polymerized for 10 seconds prior to the application of the composite. For CSEB adhesive system, the self-etching primer was applied with a brush and dried with mild air flow after 20 seconds. The bond liquid was then applied and evenly distributed with a gentle air stream, and light-cured for 10 seconds. The CS3 adhesive was applied and dried with air high-pressure after 20 seconds and then light-cured for 10 seconds.

For the selective bonding groups, after the hybridization of the entire cavity surface, the 
margins of the preparations were refinished with a super-fine diamond bur (Komet, Lemgo, Germany) and then a new adhesive procedure was carried out only on the cavity finish lines. The etch-and-rinse adhesive systems (SMP and SB) were applied after a new etching procedure and the primer of SMP was not used. The self-etch adhesive systems (CSEB and CS3) were applied immediately after the refinishing procedure, following the protocol already described. As previously mentioned, the objective of this technique is to achieve a new and strong adhesion on the margins of the cavity (to prevent gaps and microleakage) while maintaining a good quality of dentinal sealing (provided by the first adhesive procedure).

The composite resin Z250 shade A2 (3M Espe, St Paul, MN, USAl was inserted in 3 increments and each layer was light-cured for 40 seconds. For the groups where flowable composite was used as a liner, the flowable composite Filtek Flow (3M Espe, St Paul, MN, USA) was applied as an initial layer before the 3 increments of conventional composite, and then light-cured for 40 seconds.

After the polymerization of the last increment of composite, the distance between the glass balls was measured and recorded as 'final distance'. The cuspal movement was obtained by calculating the difference between 'final' and 'initial' measurements. The results were subjected to statistical analysis by ANOVA and Tukey's HSD paired group post hoc comparison procedure test.

\section{RESULTS}

The influence of the bonding technique on the cuspal movement was statistically significant $(P<.01)$ for all the adhesive systems evaluated in this study. The results observed with etchand-rinse and self-etch adhesive systems are shown respectively in Tables 2 and 3. For all adhesive systems, there were statistically significant differences among selectively and totally bonded groups. The teeth restored with selective bonding technique showed lower values of cuspal movement and an intermediary layer of flowable composite did not show any influence on the cuspal movement. No differences were found between the materials of each category letch-andrinse and self-etch), except between SMP and SB totally bonded associated to flowable composite.

\section{DISCUSSION}

It is largely accepted that volumetric contraction during polymerization of restorative composites in association with bond to the hard tissues results

Table 1. Groups established.

\begin{tabular}{lccc}
\hline Groups & Material & Adhesive protocol & Flowable composite \\
\hline Group I & SMP & total & no \\
Group II & SMP & total & yes \\
Group III & SMP & selective & no \\
Group IV & SMP & selective & yes \\
Group V & SB & total & no \\
Group VI & SB & total & yes \\
Group VII & SB & selective & no \\
Group VIII & SB & selective & yes \\
Group IX & CSEB & total & yes \\
Group X & CSEB & total & no \\
Group XI & CSEB & selective & yes \\
Group XII & CSEB & selective & no \\
Group XIII & CS3 & total & yes \\
Group XIV & CS3 & total & no \\
Group XV & CS3 & selective & yes \\
Group XVI & CS3 & selective & \\
\hline
\end{tabular}


in stress transfer and inward deformation of the cavity walls of the restored tooth. ${ }^{10}$ Mechanical stresses produced by shrinkage of the composite restorative material associated to high adhesive bond strengths may be transmitted to the surrounding tooth structure. ${ }^{11}$

In total bonding technique, if the adhesion is stronger than the polymerization shrinkage stress and/or stresses under function, the interface between restoration and tooth remains perfectly sealed. However, shrinkage stresses may become higher than the bond strengths, resulting in partial debonding of the adhesive from the tooth surface. ${ }^{6}$

Total bonding technique is the simplest adhesive technique and may be indicated in restorations with a small volume and/or a low C-factor (fissure sealing, small class I and III composite restorations, large flat onlays). Selective bonding is better indicated for large class I and III composite restorations and for class II composite fillings, inlays and small onlays. ${ }^{6}$ Selective bonding technique creates free surfaces within the cavity, thus reducing the $\mathrm{C}$-factor of the restoration. It has been suggested the use of glass-ionomer cement (GIC) as a liner or base in the selective bonding technique. The GIC can seal dentin and must be insulated to prevent this material from adhering to the restorative composite. In the present study, when proceeding with selective bonding technique, the same adhesive system to be tested was used as a dentin sealer, followed by refinishing of the margins and a new bonding procedure on the freshly cut tooth surface. The adhesion between the two coats of adhesive system was prevented by the contamination of the first surface by water and contaminants created during the refinishing procedure. It is accepted that beveling of enamel margins decreases the

Table 2. Means of cuspal displacement $(\mu \mathrm{m})$, standard deviation (SD) and coefficient of variation (\%) for the etchand-rinse adhesives (SMP and SB). Within each line, different lower case letters mean statistically difference; within each column, different capital letters mean statistically significant difference $(P<.05)$.

\begin{tabular}{|c|c|c|}
\hline Adhesive protocol & SMP & SB \\
\hline \multirow{2}{*}{ Total } & 23.50 (3.92) A,a & $21.19(3.14) \quad A, a$ \\
\hline & $16.72 \%$ & $14.85 \%$ \\
\hline \multirow{2}{*}{ Total / flow } & $24.56(4.51) \quad A, a$ & $19.18(4.05) \quad A, b$ \\
\hline & $18.39 \%$ & $21.12 \%$ \\
\hline \multirow{2}{*}{ Selective } & $14.16(3.17) \quad B, a$ & $12.61(3.78) \quad B, a$ \\
\hline & $22.42 \%$ & $30.02 \%$ \\
\hline \multirow{2}{*}{ Selective / flow } & $11.63(3.34) \quad B, a$ & $12.62(2.80) \quad B, a$ \\
\hline & $28.77 \%$ & $22.22 \%$ \\
\hline
\end{tabular}

Table 3. Means of cuspal displacement $(\mu \mathrm{m})$, standard deviation (SD) and coefficient of variation (\%) for the selfetch adhesives (CSEB and CS3). Within each line, different lower case letters mean statistically difference; within each column, different capital letters mean statistically significant difference $(P<.05)$.

\begin{tabular}{|c|c|c|c|}
\hline Adhesive protocol & CSEB & CS3 & \\
\hline \multirow{2}{*}{ Total } & $24.18(4.05) \quad A, a$ & 21.88 (3.29) & $A, a$ \\
\hline & $16.78 \%$ & $15.05 \%$ & \\
\hline \multirow{2}{*}{ Total / flow } & $22.47(4.21) \quad A, a$ & $21.83(2.81)$ & $A, a$ \\
\hline & $18.75 \%$ & $12.91 \%$ & \\
\hline \multirow{2}{*}{ Selective } & $12.89(5.27) \quad B, a$ & 13.62 (3.52) & $\mathrm{B}, \mathrm{a}$ \\
\hline & $40.96 \%$ & $25.87 \%$ & \\
\hline \multirow{2}{*}{ Selective / flow } & $12.38(3.48) \quad B, a$ & $12.84(3.48)$ & $\mathrm{B}, \mathrm{a}$ \\
\hline & $28.15 \%$ & $27.14 \%$ & \\
\hline
\end{tabular}


risk of marginal gaps, microleakage and enamel fractures. ${ }^{12}$ Additionally, it has been demonstrated that self-etch adhesives show higher values of bond strength on ground enamel compared to intact enamel. ${ }^{13}$ This last statement is also supported by recent reports using CSEB $^{14}$ and CS315 self-etch adhesive systems.

The cavities utilized in this study were large MOD cavities with a high $\mathrm{C}$-factor and remaining tooth structure weakened, to facilitate the cuspal movement during restoration. ${ }^{9}$ The $\mathrm{C}$-factor was reduced when using selective bonding technique, which seems to be favorable in reducing cuspal movement for all the adhesive systems tested.

All experimental groups showed a reduction in intercuspal distance after the restorative procedure. However, the values of this displacement were significantly lower when selective bonding technique was employed. Numerous factors, such as hydration of dentin, flow, creep, hygroscopic expansion of the material, and fracture within the tooth structure determine the recovery of cuspal deformation to its original position, ${ }^{11,16-18}$ but the total recovery of the initial distance is never complete in medium-size and large restorations.,319

The use of flowable composites as a liner has been proposed to diminish the effects of polymerization shrinkage because they have a low modulus of elasticity and can absorb the stress generated during polymerization. 16,20,21 Van Meerbeek et $\mathrm{al}^{22}$ have observed that the use of a low modulus flowable composite may increase the flexibility of the bonded assembly, allowing it to act as a stress breaker. However, considering the same adhesive protocol (total bonding or selective bonding), the cuspal displacement was statistically similar for all the adhesive systems, independently of the use of flowable composite as a liner.

It is important to emphasize the importance of the development of resinous filling materials with lower polymerization shrinkage. This, associated to effective bond strengths, appropriate cavity designs and techniques, will facilitate the obtaining of a stable sealing of composites in dental hard tissues with no significant cuspal movement.

\section{CONCLUSIONS}

All groups submitted to total bonding technique showed higher levels of cuspal movement compared to the groups submitted to selective bonding technique. However, the cusp movement was not completely prevented with the selective bonding technique. The use of an intermediate layer of flowable composite did not show any influence on the cuspal movement. The results of this in vitro study should be confirmed by longterm clinical evaluations.

\section{REFERENCES}

1. Gonzalez Lopez S, Sanz Chinesta MV, Ceballos Garcia L, de Haro Gasquet F, Gonzalez Rodriguez MP. Influence of cavity type and size of composite restorations on cuspal flexure. Med Oral Patol Oral Cir Bucal 2006;11:E536-540.

2. Krejci I, Duc O, Dietschi D, de Campos E. Marginal adaptation, retention and fracture resistance of adhesive composite restorations on devital teeth with and without posts. Oper Dent 2003;28:127-135.

3. Gonzalez-Lopez S, Lucena-Martin C, de Haro-Gasquet F, Vilchez-Diaz MA, de Haro-Munoz C. Influence of different composite restoration techniques on cuspal deflection: an in vitro study. Oper Dent 2004;29:656-660.

4. Fleming GJ, Hall DP, Shortall AC, Burke FJ. Cuspal movement and microleakage in premolar teeth restored with posterior filling materials of varying reported volumetric shrinkage values. J Dent 2005;33:139-146.

5. Lutz F, Krejci I, Barbakow F. Quality and durability of marginal adaptation in bonded composite restorations. Dent Mater 1991;7:107-113.

6. Krejci I, Stavridakis M. New perspectives on dentin adhesion--differing methods of bonding. Pract Periodontics Aesthet Dent 2000;12:727-732; quiz 734.

7. Goehring TN, Peters OA, Lutz F. Marginal adaptation of inlay-retained adhesive fixed partial dentures after mechanical and thermal stress: an in vitro study. J Prosthet Dent 2001;86:81-92.

8. Campos EA, Correr GM, Leonardi DP, Barato-Filho F, Gonzaga CC, Zielak JC. Chlorhexidine diminishes the loss of bond strength over time under simulated pulpal pressure and thermo-mechanical stressing. J Dent 2009;37:108-114.

9. Versluis A, Douglas WH, Cross M, Sakaguchi RL. Does an incremental filling technique reduce polymerization shrinkage stresses? J Dent Res 1996;75:871-878.

10. Meredith N, Setchell DJ. In vitro measurement of cuspal strain and displacement in composite restored teeth. $J$ Dent 1997;25:331-337. 
11. Opdam NJ, Roeters JJ, Kuijs R, Burgersdijk RC. Necessity of bevels for box only Class II composite restorations. $J$ Prosthet Dent 1998;80:274-279.

12. Alomari QD, Reinhardt JW, Boyer DB. Effect of liners on cusp deflection and gap formation in composite restorations. Oper Dent 2001;26:406-411.

13. Senawongse $P$, Sattabanasuk V, Shimada $Y$, Otsuki $M$, Tagami J. Bond strengths of current adhesive systems on intact and ground enamel. J Esthet Restor Dent 2004;16:107115; discussion 116

14. Sengun A, Orucoglu H, Ipekdal I, Ozer F. Adhesion of two bonding systems to air-abraded or bur-abraded human enamel surfaces. Eur J Dent 2008;2:167-175.

15. Reis A, Moura K, Pellizzaro A, Dal-Bianco K, de Andrade $A M$, Loguercio AD. Durability of enamel bonding using onestep self-etch systems on ground and unground enamel. Oper Dent 2009;34:181-191.

16. Krejci I, Schupbach P, Balmelli F, Lutz F. The ultrastructure of a compomer adhesive interface in enamel and dentin, and its marginal adaptation under dentinal fluid as compared to that of a composite. Dent Mater 1999;15:349358.

17. Causton BE, Miller B, Sefton J. The deformation of cusps by bonded posterior composite restorations: an in vitro study. Br Dent $J$ 1985;159:397-400.

18. Tantbirojn D, Versluis A, Pintado MR, DeLong R, Douglas $\mathrm{WH}$. Tooth deformation patterns in molars after composite restoration. Dent Mater 2004;20:535-542.

19. Segura A, Donly KJ. In vitro posterior composite polymerization recovery following hygroscopic expansion. J Oral Rehabil 1993;20:495-499.

20. Bayne SC, Thompson JY, Swift EJ, Jr., Stamatiades P, Wilkerson M. A characterization of first-generation flowable composites. J Am Dent Assoc 1998;129:567-577.

21. Olmez A, Oztas $\mathrm{N}$, Bodur $\mathrm{H}$. The effect of flowable resin composite on microleakage and internal voids in class II composite restorations. Oper Dent 2004;29:713-719.

22. Van Meerbeek B, Willems G, Celis JP, Roos JR, Braem M, Lambrechts P, Vanherle G. Assessment by nanoindentation of the hardness and elasticity of the resindentin bonding area. J Dent Res 1993;72:1434-1442. 